\title{
Diagnosis of Hereditary Spherocytosis and Secondary Hemochromatosis in a Patient with Jaundice
}

\author{
Yidan Gao Binbin Zhang Yiran Song Ge Li Yanting Bao Yanming Jiang Ling Gao \\ Gongying Chen Jie Wang
}

Department of Hepatology, The Affiliated Hospital of Hangzhou Normal University, Hangzhou, China

Hereditary spherocytosis (HS) is a type of hemolytic anemia resulting from hereditary defects in the erythrocyte membrane. The main clinical features are anemia, jaundice, splenomegaly, gallstones, visible spherical red blood cells (RBC) in the peripheral blood, and increased RBC osmotic fragility. The pathological cause of $\mathrm{HS}$ is a genetic mutation that leads to an RBC membrane protein deficiency, increased cell permeability, decreased deformability, and increased damage to the spleen. The genes involved are ANK1, SLC4A1, SPTA1, SPTB, EPB42, and EPB41; ANK1 mutations are the most common $[1,2]$. Splenectomy is an effective and safe treatment for HS symptom relief, especially in children $[3,4]$. With sporadic treatment, the misdiagnosis and missed diagnosis rates are high [5]. The incidence of HS is reportedly much higher than the clinical diagnosis rate [6]. Morton et al. [7] studied the genetic characteristics of HS and found that while HS can occur in all ethnic groups, its genetic frequency remains unknown. Approximately $75 \%$ of cases are autosomal dominant, and the ANK1 gene is most commonly mutated. The other $25 \%$ cases are autosomal recessive; in these cases, although there may be no family history, other relatives may also have gene mutations, phenotypic variations, and autosomal recessive inheritance [8].
According to the 2011 guidelines for HS diagnosis and management of the General Haematology Task Force of the British Committee for Standards in Haematology, HS can be diagnosed without further tests if a patient has the combination of a family history of HS and typical HS clinical manifestations and blood parameters. Currently, there are no laboratory tests for an HS diagnosis alone; the combination of the eosin-maleimide test (EMA) with the acidified glycerol lysis test (AGLT) is the first choice, and it has a sensitivity of almost $100 \%$. The sensitivity of the combination of the erythrocyte osmotic fragility test (OFT) with AGLT is $97 \%$, while that of the combination of the EMA and the OFT is $95 \%$. If the patient's blood smear results are positive, the family members will be recommended to undergo the OFT and EMA, too [9]. Patients with normal blood smears from the parents will be screened for molecular defects, which may indicate recessive inheritance resulting from new mutations in the SPTB and ANK1 genes. Further analysis of the SPTB and ANK1 genes of patients and their families may reveal new single-allele gene expression as the cause of the disease [10].

Here, we found a novel pathogenic mutation in ANK1. We present the case of a 51-year-old man repeatedly experiencing fatigue and yellow urine for 10 years. The patient had undergone cholecystectomy. He had suffered hyperbilirubinemia and had undergone a bone marrow puncture when he was an infant (data not available). There is no similar history in his family. Laboratory tested revealed the following: white blood cell count, $6.14 \times 10^{9} / \mathrm{L}$; RBC count, $3.39 \times 10^{12} / \mathrm{L}$; hemoglobin, $99 \mathrm{~g} / \mathrm{L}$; mean corpuscular volume, $83.8 \mathrm{fL}$; platelet count, $145 \times 10^{9} / \mathrm{L}$; reticulocyte count, 9.41\%; total bilirubin, $96.2 \mu \mathrm{mol} / \mathrm{L}$ (reference value: $1.7-25.6 \mu \mathrm{mol} / \mathrm{L}$ ); indirect bilirubin, $79.7 \mu \mathrm{mol} / \mathrm{L}$ (reference value: $0.1-21$ $\mu \mathrm{mol} / \mathrm{L})$; total iron binding capacity, 51.4 $\mu \mathrm{mol} / \mathrm{L}$; iron, $12.5 \mu \mathrm{mol} / \mathrm{L}$; transferrin saturation, $24.3 \%$; ferritin, $523.41 \mu \mathrm{g} / \mathrm{L}$; copper protein, $282 \mathrm{mg} / \mathrm{L}$. B ultrasound revealed hepatomegaly and splenomegaly. Peripheral blood smear showed $40 \%$ spherical RBCs by microscopy. The erythrocyte OFT was normal. For differential diagnosis, the patient underwent the following tests: sucrose hemolysis, serum acidification hemolysis, Coombs, alkali denaturation, hemoglobin $\mathrm{A}_{2}$, hemoglobin electrophoresis, hemoglobin $\mathrm{H}$ inclusion body, modified globin body, isopropyl alcohol, methemoglobin reduction, glucose 6-phosphate dehydrogenase fluorescent spot, and glucose 6-phosphate dehydrogenase activity tests, all of which yielded normal results.

\section{KARGER}

(C) 2018 S. Karger AG, Basel

E-Mail karger@karger.com

www.karger.com/aha
Jie Wang

Department of Hepatology

The Affiliated Hospital of Hangzhou Normal University

Hangzhou, Zhejiang 310000 (China)

E-Mail littlecat_419@163.com 
Table 1. Gene mutations

\begin{tabular}{|c|c|c|c|c|c|c|c|}
\hline ANK1 & c. $2803 \mathrm{C} \rightarrow \mathrm{T}$ & p.R935X & 26 & het-var & chr8:41554038 & & nonsense/damaging \\
\hline ANK1 & c. $5265 \mathrm{G} \rightarrow \mathrm{A}$ & p.V1755V & 39 & hom-var & chr8:41525914 & rs750625 & synonymous \\
\hline ANK1 & c. $315 \mathrm{C} \rightarrow \mathrm{T}$ & p.N105N & 74 & het-var & chr8:41585438 & rs2304871 & synonymous \\
\hline SPTA1 & c.7095 A $\rightarrow \mathrm{G}$ & p.A2365A & 51 & het-var & chr1:158582646 & rs2251969 & synonymous \\
\hline SPTA1 & c. $6794 \mathrm{~T} \rightarrow \mathrm{C}$ & p.I2265T & 49 & het-var & chr1:158584091 & rs952094 & missense/benign \\
\hline SPTA1 & c. $5572 \mathrm{C} \rightarrow \mathrm{G}$ & p.L1858V & 40 & het-var & chr1:158597507 & rs3737515 & missense/benign \\
\hline SPTA1 & c. $5292 \mathrm{C} \rightarrow \mathrm{A}$ & p.A1764A & 37 & het-var & chr1:158606449 & rs3738791 & synonymous \\
\hline SPTA1 & c. $4702 \mathrm{~T} \rightarrow \mathrm{C}$ & p.C1568R & 33 & het-var & chr1:158612236 & rs863931 & missense/benign \\
\hline SPTA1 & c. $3487 \mathrm{~T} \rightarrow \mathrm{G}$ & p.S1163A & 25 & hom-var & chr1:158619728 & rs2482965 & missense/benign \\
\hline SPTA1 & c. $2874 \mathrm{G} \rightarrow \mathrm{A}$ & p.L958L & 20 & het-var & chr1:158626378 & rs857691 & synonymous \\
\hline SPTA1 & c. $2493 \mathrm{~T} \rightarrow \mathrm{G}$ & p.L831L & 18 & het-var & chr1:158631171 & rs2518493 & synonymous \\
\hline SPTB & c. $4641 \mathrm{G} \rightarrow \mathrm{A}$ & p.A1547A & 22 & het-var & chr14:65242044 & rs184528 & synonymous \\
\hline SPTB & c. $1316 \mathrm{G} \rightarrow \mathrm{A}$ & p.S439N & 10 & het-var & chr14:65263300 & rs229587 & missense/benign \\
\hline SPTB & c. $1269 \mathrm{G} \rightarrow \mathrm{A}$ & p.L423L & 10 & het-var & chr14:65263347 & rs229586 & synonymous \\
\hline
\end{tabular}

Therefore, the diagnosis of HS was confirmed. In addition, upper abdominal nuclear magnetic resonance (NMR) spectroscopy revealed iron deposition in the liver and spleen. A liver biopsy indicated liver hemosiderosis with mild fibrosis, and, in view of the normal transferrin saturation, he was diagnosed with secondary hemochromatosis.

Then, we detected 6 exons of HS-related genes through next-generation highthroughput sequencing. Analyzing the function of and variation in each gene, it was found that the ANK1, SPTA1, and SPTB genes were mutants (Table 1) without SLC4A1, EPB42, or EPB41 gene mutations. According to the classification of genetic variants published by the American College of Medical Genetics and Genomics (ACMG), ANK1 (MN_000037.3) exon 26: c. $2803 \mathrm{C} \rightarrow \mathrm{T}$ was suspected pathogenic mutation, which was ultimately verified by Sanger sequencing (Fig. 1). His father had passed away and had no clinical manifestations while alive, and the blood smear results of the patient's mother, son, and daughter were all normal. Therefore, it was considered a novel nonsense mutation.

In summary, as HS is prone to be misdiagnosed and missed altogether, relevant medical projects should be performed thoroughly in medical institutions. Clinicians should also raise the awareness of HS

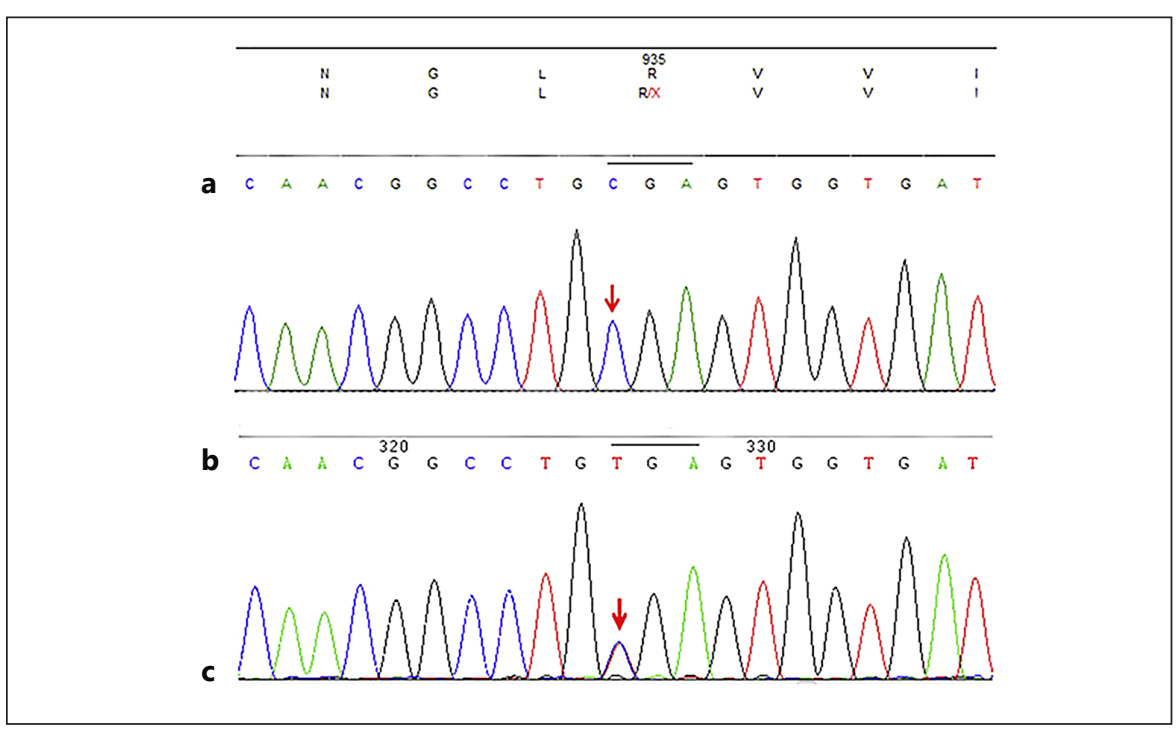

Fig. 1. Sanger sequencing results. a The 935th amino acid changed from arginine to a stop codon. b, c Sanger sequencing results of the reference base sequence (b) and the patient's base sequence (c). b Arrow indicates the ANK1 gene c.2803 site, which was normal. c Arrow indicates the heterozygous mutation in the ANK1 gene: c. $2803 \mathrm{C} \rightarrow \mathrm{T}$.

and take it into account, especially in cases of unexplained jaundice. Here, we diagnosed a patient with HS and secondary hemochromatosis, and we found a novel nonsense mutation. Moreover, we used a new technique, upper abdominal NMR spec- troscopy, to assess the iron content of the liver, which could help predicting the prognosis. However, further clinical studies still need to be performed to explore the genetic types and hereditary characteristics of HS. 


\section{References}

$\checkmark 1$ Yang MQ, Laflamme K, Gotea V, Joiner CH, Seidel NE, Wong C, Petrykowska HM, Lichtenberg J, Lee S, Welch L, Gallagher PG, Bodine DM, Elnitski L: Genome-wide detection of a TFIID localization element from an initial human disease mutation. Nucleic Acids Res 2011;39:2175-2187.

-2 Gundel F, Eber S, Heep A: A new ankyrin mutation (ANK1 exon E9X) causing severe hereditary spherocytosis in the neonatal period. Ann Hematol 2011;90:231-232.

3 Abdullah F, Zhang Y, Camp M, Rossberg MI, Bathurst MA, Colombani PM, Casella JF, Nabaweesi R, Chang DC: Splenectomy in hereditary spherocytosis: review of $1,657 \mathrm{pa}-$ tients and application of the pediatric quality indicators. Pediatr Blood Cancer 2009;52: 834-837.
4 Rescorla FJ, West KW, Engum SA, Grosfeld JL: Laparoscopic splenic procedures in children. Ann Surg 2007;246:687-688.

5 Deng Z, Liao L, Yang W, Lin F: Misdiagnosis of two cases of hereditary spherocytosis in a family and review of published reports. Clin Chim Acta 2015;441:6.

-6 Kutter D: Hereditary spherocytosis is more frequent than expected: what to tell the patient? Bull Soc Sci Med Grand Duche Luxemb 2005; 1:7-22.

7 Morton NE, Mackinney AA, Kosower N, Schilling RF, Gray MP: Genetics of spherocytosis. Am J Hum Genet 1962;14:170-184.
8 Greth A, Lampkin S, Mayura-Guru P, Rodda F, Drysdale K, Roberts-Thomson M, McMorran BJ, Foote SJ, Burgio G: A novel ENU-mutation in ankyrin-1 disrupts malaria parasite maturation in red blood cells of mice. PLoS One 2012;7:e38999.

\9 King MJ, Behrens J, Rogers C, Flynn C, Greenwood D, Chambers K: Rapid flow cytometric test for the diagnosis of membrane cytoskeleton-associated haemolytic anaemia. $\mathrm{Br}$ J Haematol 2000;111:924-933.

10 Delaunay J: The molecular basis of hereditary red cell membrane disorders. Blood Rev 2007; 21:1-20. 